\title{
Three-dimensional models: an emerging investigational revolution for craniovertebral junction surgery
}

\author{
Atul Goel, MCh, ${ }^{1,2}$ Bhavin Jankharia, MD, ${ }^{3}$ Abhidha Shah, $\mathrm{MCh},{ }^{1}$ and Prashant Sathe, $\mathrm{MCh}^{1}$ \\ ${ }^{1}$ Department of Neurosurgery, K.E.M. Hospital and Seth G.S. Medical College; ${ }^{2}$ Lilavati Hospital and Research Centre; and \\ ${ }^{3}$ Jankharia Imaging Center, Mumbai, India
}

Complex craniovertebral junctional anomalies can be daunting to treat surgically, and preoperative information regarding the osseous abnormalities, course of the vertebral arteries, size of the pedicles, and location of the transverse foramina is invaluable to surgeons operating on these challenging cases. The authors present their experience with the emerging technology of 3D model acquisition for surgery in 11 cases of complex craniovertebral junction region anomalies.

For each case, a 3D printed model was made from thin CT scans using a 64-slice CT scanner. The inclination of the joints, the presence of false articulations, the size of the pedicles, and the course of the vertebral arteries were studied preoperatively on the 3D models. The sizes of the plates and screws to be used and the angle of insertion of the screws were calculated based on the data from the models. The model was scaled to actual size and was kept beside the operating surgeon in its anatomical position during surgery. The potential uses of the models and their advantages over conventional radiological investigations are discussed.

The authors conclude that 3D models can be an invaluable aid during surgery for complex craniovertebral junction anomalies. The information available from a real life-size model supersedes the information available from 3D CT reconstructions and can also be superior to virtual simulation. The models are both cost effective and easy to build and the authors suggest that they may form the basis of investigations in the near future for craniovertebral junction surgery. http://thejns.org/doi/abs/10.3171/2016.4.SPINE151268

KEY WORDS 3D printing; atlantoaxial instability; basilar invagination; craniovertebral junction; technique

$\mathrm{S}$ URGERY for craniovertebral junctional anomalies can be a technical challenge. Exposure of the atlantoaxial joint can be relatively complex, particularly in patients with basilar invagination and neck deformities. Exact preoperative understanding of the location of the vertebral artery and its course in relationship with the facet of axis and in the region of the arch of atlas as well as evaluation of the dimensions of the bones and their orientation for identifying the best trajectory of screw implantation can be crucial for the success of surgery. 3D models provide a clear anatomical evaluation of the operative area in question. The model can be used to practice the operation prior to the actual surgery and prepare the sizes of implants that may be necessary. The simulated models can also be used as teaching tools and as aids for patient education and counseling.

\section{Methods}

Over a 4-month period (May-August 2015), 3D models were printed from thin-slice CT scans obtained in 11 patients with "complex" craniovertebral anomalies. All of the patients selected had varying degrees of short neck and torticollis. They had relatively complex craniovertebral bone and soft tissue organization.

\section{Data Acquisition}

The CT scan data were acquired using a 64-slice scanner (Somatom 64). The scan was obtained from a level approximately $2 \mathrm{~cm}$ superior to the posterior margin of the foramen magnum up to the T-1 vertebra, after injection of $60 \mathrm{ml}$ of iodinated contrast and a $20-\mathrm{ml}$ saline chaser at $4.5 \mathrm{ml} / \mathrm{second}$. The scan was triggered 12 seconds after 
completion of the injection to obtain a vertebral and carotid angiogram study along with visualization of the bone structure. Axial $0.75-\mathrm{mm}$-thick images were obtained at 0.5 -mm intervals.

\section{D File Creation}

The axial volume images were then transferred to a specialized workstation (Vizua), where the 3D volume was created. All structures not required were edited out, and the volume generated included the craniovertebral junction, foramen magnum, clivus, and part of the occipital and temporal bone, as well as the cervical vertebrae down to C-7 (Fig. 1). Using another radiology viewing program (Osirix 6.0), it was ensured that the model being edited was life size or true to size. The color filters were adjusted to maximize the contrast between the bones and the vertebral arteries. This 3D volume was then exported to a .zpr file.
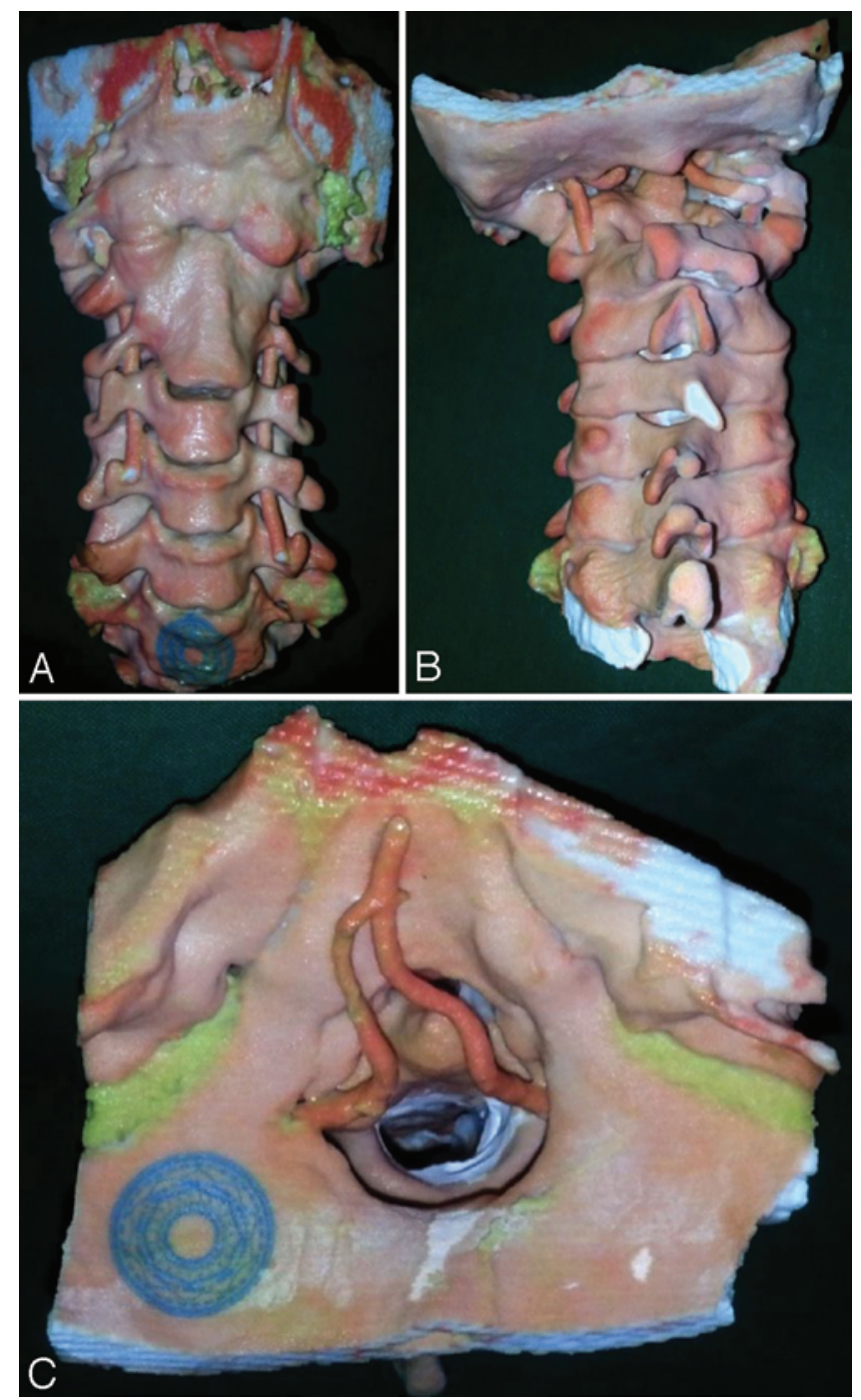

FIG. 1. Case 1. A: 3D model showing the anatomy of the craniovertebral junction from an anterior perspective. B: 3D model showing the anatomy from a posterior perspective. The vertebral artery has an abnormal course posterior to the facets of the atlas. C: 3D model from a superior perspective showing the vertebral arteries and their intracranial course. Figure is available in color online only.

\section{D Model Creation}

The .zpr file was then transferred to the workstation of a color jet 3D printer (Projet 660, 3D Systems), and the model was placed on the tray simulator. Its position was adjusted to minimize its $\mathrm{Z}$-axis length, so as to optimize the $3 \mathrm{D}$ printing time. The average print time for the cervical spine model inclusive of the craniovertebral junction was between 2 and 3 hours. After an additional 2 hours of cooling, the part was removed and fixed.

\section{Analysis of Experience}

Eleven patients having complex craniovertebral junction instability underwent atlantoaxial facetal fixation with the techniques discussed in our articles on the subject. ${ }^{6-9}$ The ages of the patient ranged from 10 to 49 years. There were 8 males and 3 females in the series. All the patients had neck pain and spastic quadriparesis. Their preoperative and postoperative neurological deficits are summarized in Table 1. The patients were assessed based on the 5 -point clinical grading system recently described by us ${ }^{5}$ to assess disability related to craniovertebral junction region myelopathy and by the Japanese Orthopaedic Association scoring system. ${ }^{3}$ All patients had complex craniovertebral junctional anomalies and a number of bone and soft tissue abnormalities (summarized in Table 1). Ten of 11 patients in the series had basilar invagination. One patient had os odontoideum and atlantoaxial dislocation. There was a complete or partial occipitalization of the atlas in 7 patients and a bifid arch of the atlas in 1 patient. The joints were abnormally inclined in 10 patients. In 3 patients there were abnormal posterior fusions, between $\mathrm{C}-1$ and $\mathrm{C}-2$ in 2 patients and between the foramen magnum and C-2 in 1 patient. The true C-1 and C-2 joints were anterior to these abnormal fusions, which had to be drilled before the joints could be approached. In 4 patients the vertebral artery had an abnormal course and traversed posterior to the atlantoaxial articulation, obscuring its view during dissection. The artery was displaced superiorly and appropriately protected during screw implantation.

As per our surgical philosophy, all patients underwent direct atlantoaxial lateral mass fixation, and the occipital bone was not included in the fixation construct. Although intraoperative fluoroscopy and image-guided surgery can be additionally used during surgery, neither of these modalities were deployed in the presented patient subgroup. We envisage that further improvement in the technology can provide a real-time intraoperative 3D model reconstruction that will further increase the safety and strength of screw insertion. The atlantoaxial joint was widely opened, articular cartilage was denuded, bone graft was placed in the joint cavity, and direct lateral mass plate/rod and mono/ polyaxial screw fixation was performed. The C-2 ganglia were resected bilaterally in 6 patients to facilitate wide joint exposure and conduct of the surgical procedure. ${ }^{4} \mathrm{In}$ all cases the patients' condition improved after the surgical procedure and there was no significant intraoperative event such as vertebral artery injury or difficulty in placement of the implant.

The model provided a useful tool to evaluate the anatomy of the region in a 3D perspective and to prepare for the surgical procedure in all cases in our series. The 
TABLE 1. Summary of the demographic, clinical, and radiological characteristics of 11 patients

\begin{tabular}{|c|c|c|c|c|c|c|}
\hline $\begin{array}{l}\text { Case } \\
\text { No. }\end{array}$ & $\begin{array}{c}\text { Age (yrs), } \\
\text { Sex }\end{array}$ & $\begin{array}{l}\text { Preop } \\
\text { Grade }\end{array}$ & $\begin{array}{l}\text { Preop JOA } \\
\text { Score }\end{array}$ & Radiological Findings & $\begin{array}{l}\text { Postop } \\
\text { Grade }\end{array}$ & $\begin{array}{c}\text { Postop JOA } \\
\text { Score }\end{array}$ \\
\hline 1 & $10, M$ & 2 & 15 & BI w/ assimilation of atlas, torticollis, \& Type A atlantoaxial facetal dislocation & 1 & 17 \\
\hline 2 & $11, \mathrm{M}$ & 2 & 15 & BI w/ Type A atlantoaxial facetal dislocation & 1 & 17 \\
\hline 3 & $14, \mathrm{~F}$ & 4 & 8 & Atlantoaxial dislocation w/ os odontoideum \& torticollis & 2 & 14 \\
\hline 4 & $30, \mathrm{M}$ & 2 & 15 & BI w/ partial assimilation of atlas \& Type A atlantoaxial facetal dislocation & 1 & 17 \\
\hline 5 & $45, \mathrm{~F}$ & 3 & 10 & $\begin{array}{l}\text { BI w/ assimilation of atlas, Type A atlantoaxial facetal dislocation, torticollis, \& bilat } \\
\text { facetal rotation }\end{array}$ & 2 & 15 \\
\hline 6 & $32, \mathrm{M}$ & 4 & 8 & $\mathrm{BI}$ w/ assimilation of atlas w/ abnormal course of rt VA & 2 & 12 \\
\hline 7 & $24, \mathrm{M}$ & 3 & 12 & $\begin{array}{l}\text { BI invagination w/ partial assimilation of atlas; thin pedicle on rt side w/ abnormal } \\
\text { course of VA dorsal to joint }\end{array}$ & 1 & 17 \\
\hline 8 & $49, \mathrm{~F}$ & 3 & 10 & $\begin{array}{l}\text { BI w/ partial assimilation of arch of atlas; abnormal fusion btwn arch \& C-2 on rt w/ } \\
\text { abnormal course of VA }\end{array}$ & 2 & 15 \\
\hline 9 & $23, \mathrm{M}$ & 2 & 14 & BI w/ Type A atlantoaxial facetal dislocation & 1 & 16 \\
\hline 10 & $22, \mathrm{M}$ & 4 & 9 & $\begin{array}{l}\text { BI w/ assimilation of atlas; abnormal fusions btwn foramen magnum \& C-2 posterior } \\
\text { to C1-2 joint; abnormal course of rt VA }\end{array}$ & 2 & 14 \\
\hline 11 & $25, \mathrm{M}$ & 2 & 14 & $\begin{array}{l}\text { BI w/ bifid posterior arch of atlas; thin pedicle on rt side w/ abnormal course of VA } \\
\text { posterior to C1-2 joint; abnormal fusion btwn C-1 \& C-2 posteriorly }\end{array}$ & 1 & 16 \\
\hline
\end{tabular}

$\mathrm{BI}$ = basilar invagination; JOA = Japanese Orthopaedic Association; VA = vertebral artery.

model could be handled and moved in various surgical positions, and the entire surgical plan could be rehearsed (Figs. 1 and 2). The ease of handling of the model made its evaluation possible even in locations other than a hospital or clinic. The size match between the model and the patient's anatomy made it possible to assess the region and to preoperatively decide on the sizes of the implants. The model helped in assessing the exact size, dominance, and course of the vertebral artery. This information assisted in evaluation of the best possible site for screw insertion, helping to avoid injury to the vertebral artery. The model assisted in identification of alternative sites or even alternative techniques for screw insertion if they were possible. The model assisted in identification of the exact location of the facets in a 3D perspective, preparation of the region that needed to be drilled, and assessment of the surgical strategy with respect to bone abnormalities, the status of facets, and facet alignment. The rotation of the region and the subsequent changes in the alignment could be evaluated directly. The model also helped in determining which atlantoaxial joint would be more easily accessible so that that side could be approached first. It gave an idea about abnormal areas of fusions and bone formation that would need to be addressed before approaching the atlantoaxial joints. Although the exact usefulness over the conventional modes of investigation is difficult to quantify, the model provides a clear feel of the altered anatomy, with a 3D perspective that provides much more information than a 2D perspective. On the whole, the models remarkably matched the intraoperative bone structures, providing a significant level of confidence during drilling and dissection of structures.

The models required approximately 5 hours to be made and the approximate cost of each model was $\$ 350$ (US). It did appear that the model assisted in providing confidence to the surgeon during surgery and reduced surgical time. The exact sizes of the screws and plates/rods could be gauged preoperatively along with the angle of insertion. The sizes of the instrumentation matched remarkably with the sizes used during the actual surgery.

The possible limitations of the model include the fact that it did not provide real-time intraoperative information. The facet alignment after the institution of the cervical traction under anesthesia could not be deciphered. The joints were fixed and the model did not provide information regarding the nature of their instability, stretchability, and suppleness. The joints observed in the model appeared to be fused probably due to the smoothing algorithm used when creating the 3D print file. However, this flaw did not affect the anatomical information about the atlantoaxial joints. The model did not provide information about the venous anatomy and the extent of venous congestion in the region of lateral gutters. Although it would be possible to make postoperative 3D models, we did not make them due to the cost involved and the fact that it would not add significant therapeutic value.

\section{Discussion}

3D printing is receiving increasing enthusiasm in the world of investigative modalities. ${ }^{1,2,10}$ Even though multidetector CT and MRI have substantially enhanced radiological diagnosis by providing 3D visualization, multiplanar reformation, and image navigation, they are limited by the use of flat screens for visualization of the 3D data. Graspable 3D objects made by 3D printing or rapid prototyping overcome this limitation and have significant potential in the diagnostic and therapeutic medical field. ${ }^{11}$ $3 \mathrm{D}$ printing is a manufacturing process in which an object is created by depositing layers of a material and merging them to create a 3D structure. Materials that can be used include plastic, ceramics, metal, powders, liquids, thermoplastic, titanium alloys, paper, photopolymers, and even living cells. The possibility of using multiple colors makes 

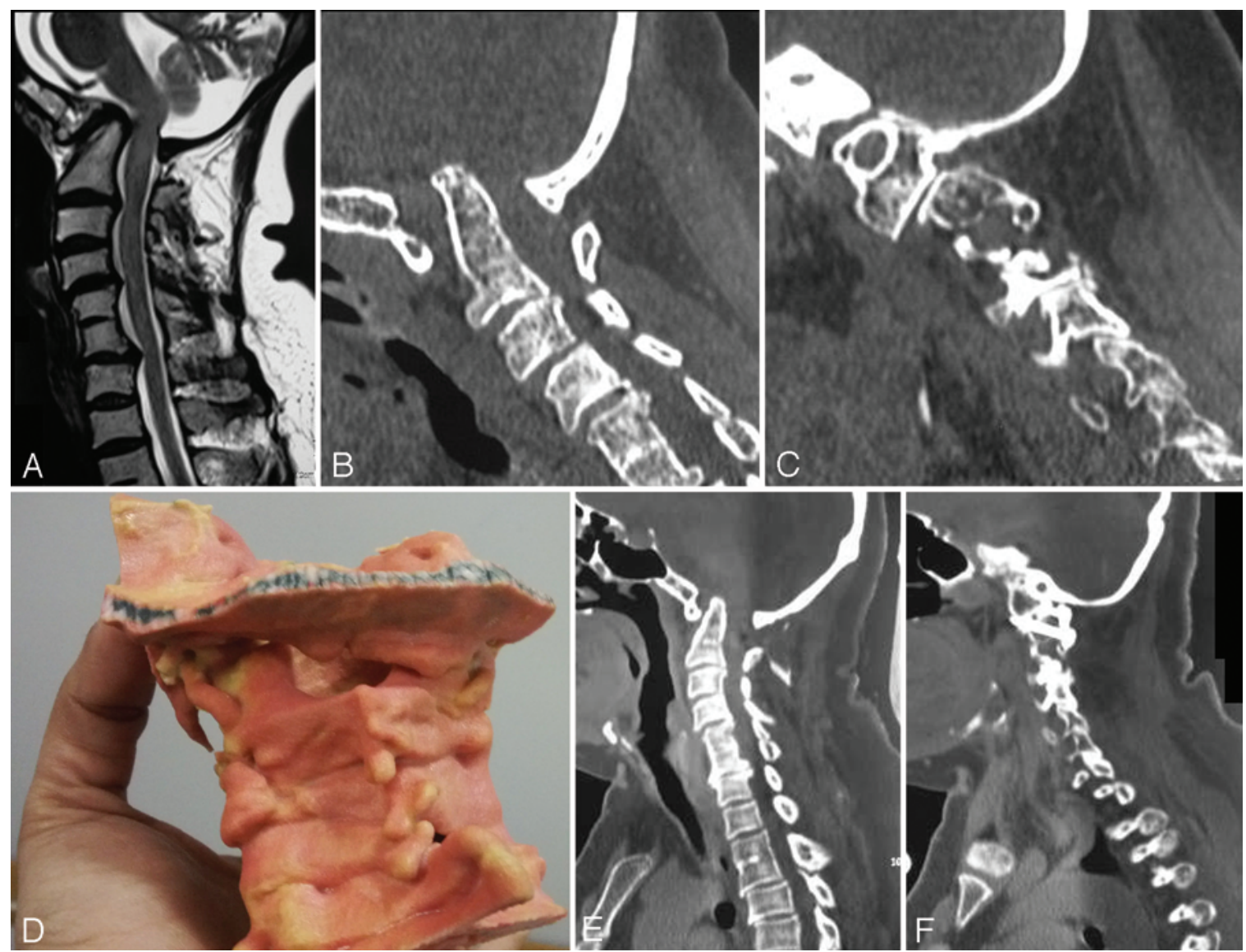

FIG. 2. Images obtained in Case 5 (involving a 45-year old woman). A: T2-weighted sagittal MR image showing basilar invagination. B: CT scan showing the basilar invagination. Assimilation of the atlas can be seen. C: Sagittal reconstruction of the CT scan with the cut passing through the facets, showing facetal instability. D: Photograph of the model used in preparation for surgery. Note the possible appreciation of alignment of facets. The location, course, and dominance of the vertebral artery can be appreciated. E: Postoperative CT scan showing distraction of facets, craniovertebral realignment, and reduction of basilar invagination. F: Sagittal reconstruction of CT scan with the cut passing through the facets, showing lateral mass plate and screw fixation. Figure is available in color online only.

it possible to introduce life-like colors for various structures, such as red for arteries and blue for veins. Charles Hull invented 3D printing in the early 1980s and called it stereolithography. ${ }^{12}$ Since then the technology has rapidly advanced and has moved into the medical field. The current medical applications of 3D printing include making customized prosthetics and implants, fabricating tissues and organs, and creating anatomical models to depict pathology. The models can be made life size for surgical simulation.

There are various methods of 3D printing, including selective laser melting, laser sintering, fused deposition modeling, stereolithography, laminated object manufacturing, and fused filament fabrication. The software needed for 3D printing is also widely available, and the cost of printing is not very high, making it a practical modality for investigation. 3D printers are very cost effective, have a good accuracy, and can make a variety of hard, soft, or flexible models. Moreover, different types of body tissues can be identified by using a predefined setting. The accuracy of the 3D printed model depends on the slice thickness of the CT scan, which should be as thin as possible.
We used a slice thickness of $0.75 \mathrm{~mm}$ to get maximum information and accuracy.

Although 3D reconstructed CT images give an overall view of the anatomy of the region, the information obtained from a 3D printed model is far superior and closer to real time. This is akin to the difference seen in the 2D image obtained by an endoscope versus a 3D image of a microscope.

A 3D printed model can aid in the production of surgical implants, improve surgical planning, act as an orientation aid during surgery, enhance diagnostic quality, and assist in preoperative simulation, counseling and achieving a patient's consent prior to surgery, and preparing a template for guiding the surgeons. ${ }^{13}$ It also is useful in providing an educational tool for medical students and residents. ${ }^{14}$

All of our treated cases of craniovertebral junction region anomalies involved complex anomalies that posed significant surgical challenges. All patients had short necks and varying degrees of torticollis. Opening of the joint and facetal manipulation and fixation can be a demanding surgical issue in such cases. Even marginal additional information can provide an increased level of comfort dur- 
ing surgery. The 3D models provided factual information about the nature of head tilt, bone anatomy, and the course of the vertebral artery. The entire course of the vertebral artery was visualized. Thus it was possible to identify any abnormalities in its course (especially in patients with assimilation of the atlas), its indentation into the superior articular facet of $\mathrm{C}-2$, and its point of entry into the cranium with respect to the posterior arch of the atlas. Thus the points of screw insertion and trajectory in the $\mathrm{C}-2$ pedicle and facet could be easily predetermined, helping to avoid inadvertent injury. The model could be handled, carried, and rotated in the desired position to evaluate the anatomy of the region. The anatomy could be rehearsed and surgical planning could be done repeatedly. The model can also be of assistance even during the surgery. It can help guide the trajectory of screw insertion and help in deciding on the sizes of the screws to be used. This is especially useful in patients with a thin $\mathrm{C}-2$ pedicle where there is a danger of cortical breech. Currently we are using fused models for preoperative planning. We envisage that in the future we will be able to simulate the unstable craniovertebral joints and judge the amount of distraction needed for reduction of complex basilar invagination.

\section{Conclusions}

On the basis of our experience in the field spanning over 3 decades, it appears to us that the technique of 3D printing can emerge to form a primary investigational modality, at least for complex craniovertebral junction anomalies.

\section{References}

1. Breimer GE, Bodani V, Looi T, Drake JM: Design and evaluation of a new synthetic brain simulator for endoscopic third ventriculostomy. J Neurosurg Pediatr 15:82-88, 2015

2. Choi JW, Kim N: Clinical application of three-dimensional printing technology in craniofacial plastic surgery. Arch Plast Surg 42:267-277, 2015

3. Fujiwara A, Kobayashi N, Saiki K, Kitagawa T, Tamai K, Saotome K: Association of the Japanese Orthopaedic Association score with the Oswestry Disability Index, RolandMorris Disability Questionnaire, and Short-Form 36. Spine (Phila Pa 1976) 28:1601-1607, 2003

4. Goel A: Cervical ganglion 2 (CG2) neurectomy: a window to the atlantoaxial joint. World Neurosurg 78:78-79, 2012

5. Goel A: Is atlantoaxial instability the cause of Chiari malfor- mation? Outcome analysis of 65 patients treated by atlantoaxial fixation. J Neurosurg Spine 22:116-127, 2015

6. Goel A: Treatment of basilar invagination by atlantoaxial joint distraction and direct lateral mass fixation. J Neurosurg Spine 1:281-286, 2004

7. Goel A, Bhatjiwale M, Desai K: Basilar invagination: a study based on 190 surgically treated patients. J Neurosurg 88:962-968, 1998

8. Goel A, Desai KI, Muzumdar DP: Atlantoaxial fixation using plate and screw method: a report of 160 treated patients. Neurosurgery 51:1351-1357, 2002

9. Goel A, Laheri VK: Plate and screw fixation for atlanto-axial dislocation.Acta Neurochir (Wien) 129:47-53, 1994

10. Liu GJ, Zhang SX, Qiu MG, Tan LW, Li QY, Li K: A novel technique for three-dimensional reconstruction for surgical simulation around the craniocervical junction region. Int Surg 96:274-280, 2011

11. Rengier F, Mehndiratta A, von Tengg-Kobligk H, Zechmann $\mathrm{CM}$, Unterhinninghofen R, Kauczor HU, et al: 3D printing based on imaging data: review of medical applications. Int $\mathbf{J}$ CARS 5:335-341, 2010

12. Ventola CL: Medical applications for 3D printing: current and projected uses. P\&T 39:704-711, 2014

13. Winder J, Bibb R: Medical rapid prototyping technologies: state of the art and current limitations for application in oral and maxillofacial surgery. J Oral Maxillofac Surg 63:1006-1015, 2005

14. Winder J, McRitchie I, McKnight W, Cooke S: Virtual surgical planning and CAD/CAM in the treatment of cranial defects. Stud Health Technol Inform 111:599-601, 2005

\section{Disclosures}

The authors report no conflict of interest concerning the materials or methods used in this study or the findings specified in this paper.

\section{Author Contributions}

Conception and design: Goel, Jankharia, Shah. Acquisition of data: all authors. Analysis and interpretation of data: Goel, Shah. Drafting the article: Goel, Shah. Critically revising the article: Goel, Jankharia, Shah. Reviewed submitted version of manuscript: all authors. Approved the final version of the manuscript on behalf of all authors: Goel. Administrative/technical/material support: Goel.

\section{Correspondence}

Atul Goel, Department of Neurosurgery, K.E.M. Hospital and Seth G.S. Medical College, Parel, Mumbai 400 012, India. email: atulgoel62@hotmail.com. 